\title{
Theory of iris photonic visual relativity: very strong proof that people with different eye colours see colours differently
}

\begin{abstract}
The purpose of this article is to present a new theoretical discovery based on certain observations in natural phenomenon such as tyndall effect ${ }^{1}$ in such a way that neurologically known retinal vision facts fit with it. According to this strange but strongly challenging way of hypothetical approach, people with different eye colours perceive colours not only in different tones such as light or navy, but they see them totally different such as what one call "orange" seem "green" to the other and that yet none of people are aware of this situation ever in their lives. The present article states with strong theoretical evidence of why this is the case using anatomically known iris light reflection. It is expected that this study will contribute visual and retinal studies in medicine.
\end{abstract}

Volume 7 Issue 5 - 2017

\author{
Mustafa Pehlivan \\ Cyprus International University, Cyprus
}

\begin{abstract}
Correspondence: Mustafa Pehlivan, Pharmaceutical Health Scientist (BSc)-University of Hertfordshire, UK Current, Cyprus International University, Bahadir sok. no 10 k. kaymakli Nicosia, Cyprus-TRNC 990I0,Tel +905338647864,
\end{abstract}

Email mustafapehlivanciu@gmail.com

Received: October II, 2017 | Published: October 30, 2017

\section{Methodology in observations and theoretical approaches}

The theoretical approach has begun with the following imagination; a little child going to the school first time, is taught in class by his/ her teacher holding a green apple saying "This apple is green". Now, even if the child sees that apple as blue or red or any other colour, obviously the child thinks "yes, this apple is green" once he/she is thaught this is the case. In fact, we all agree among people that a green looking colour is called "green" otherwise the person claiming it is blue or red is definitely "colour blind" or has visual disturbances. However, this disturbance can only be detected to be a "disturbance" if and only if that person one day starts seeing that colour different than what he/she previously saw until that day. Because of the teacher/ green apple case, if he/she keeps seeing colours as they are according to him/her during a lifetime since birth, no one can detect that he/she has colour vision disturbances, even if he/she sees every single colour differently. All people including many doctors in fact accept that many people see colours the same, but may not be the case because only with an established common language code people will call an apple seen green as "green", yet because of teacher/green apple case in the above example provided.

\section{Proof that different eye colours see every single colour totally different}

A green iris (the colorful layer covering the eye pupilla) reflects back light in "green light frequency colour" so that it is seen green. A brown iris however must reflect absorbed light back to meet "brown light frequency" level criteria so that it is seen brown. But, as they are reflecting light in different frequencies, it means that the conical cells around iris (responsible from absorbing light and passing it to the vision center of the brain where vision appears) must be passing the absorbed light there in the same frequency as the frequency of light absorbed. ${ }^{2}$ But it is known that green and brown eye colours, in order to be seen "green" and "brown" must be reflecting light in the associated "green" and "brown" light frequencies respectively. ${ }^{3}$ But since their reflected colour frequencies are different (green and brown), it means "colour" interpretation or perception of brain of the owner of that eye colour as vision itself is in different colour frequencies, which means and concludes very strong proof that although it is hard to believe or accept, green eyed person sees colours differently than that of a brown eyed person, and different visions are same way valid for all different eye colours. ${ }^{4}$ Below there is a figure showing what frequency yields to what colour appearance. (Figure 1$)^{5}$

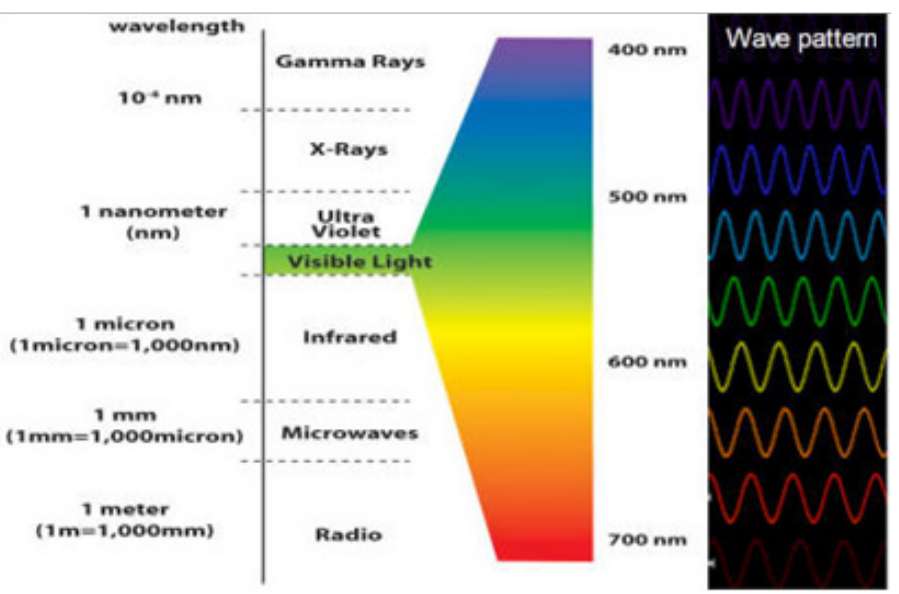

Figure I Colour frequencies.

\section{Conclusions and possible challenges in disproving this theory}

Even if Scientists find a prisma effect based evidence or think to have discovered a way to perceive how different eye colours see colours differently, or think they have a way to disprove this theory, yet they will be unable to do so. This is because anything they can detect as frequency or any attempts trying to observe how "A different eye colour is seeing colours" for the sake of a proof or disproof of 
this theory, yet what they will be expressing or observing in terms of colours yet will in fact only reflect "how they are seeing those colours differently according to their own colour vision interpretations". ${ }^{6}$ This means regardless of how much improved is or will be the Science, such an attempt will always remain invalid, unless one iris can be delivered to another person after iris removal of the person of interest so that the person receiving iris in new colour starts seeing differently. Under normal conditions unless this happens, the observer has to go out of his/her own brain and find a way to see how other people are seeing colours, which is not possible because we all need brain to see colours and visions. ${ }^{7}$ In personal opinion, the most difficult or impossible and challenging thing in life can be to provide proof or disprove an in lab based experiment or experiments for this theoretical phenomenon. But although very challenging and difficult, iris delivery can yet be the only way for a possible clinical proof.

\section{Funding source}

I, Mustafa Pehlivan as the only author of this article hereby state that this project has not received any funding and it is not related to any funding source.

\section{Acknowledgments}

None.

\section{References}

1. Rootman DB, Lin JL, Goldberg R. Does the Tyndall Effect Describe the Blue Hue Periodically Observed in Subdermal Hyaluronic Acid Gel Placement? Ophthal Plast Reconstr Surg. 2014;30(6):524-527.

2. Daugman John. How Iris Recognition Works'. IEEE transactions on circuits and systems for video technology. 2004;14(1).

3. Emotional body, Highfrequencyhealing.org.

4. Lund MF. Visual Optics: The Shapes of Pupils. Current Biology. 2006;16(5): R167-R168.

5. http://www.highfrequencyhealing.org/Emotionalbody.html

6. Gómez-Pedrero JA, Alonso J . Phenomenological model of visual acuity. J of Biomedical Optics. 2016;21(12):125005.

7. Lebensohn JE. Visual Optics and Refraction: A Clinical Approach; American Journal of Ophtalmology. 1976;81(5):694. 